\title{
SiSMI Project-Technologies for the Improvement of Safety and the Reconstruction of Historic Centres in the Seismic Area of Central Italy
}

\author{
Cristina Imbroglini *, Lucina Caravaggi and Leone Spita \\ Department of Architecture and Design, Sapienza University, 000196 Rome, Italy; \\ lucina.caravaggi@uniroma1.it (L.C.); leone.spita@uniroma1.it (L.S.) \\ * Correspondence: cristina.imbroglini@uniroma1.it
}

Received: 16 July 2020; Accepted: 14 September 2020; Published: 23 September 2020

check for updates

\begin{abstract}
The project SISMI-Tecnologie per il miglioramento della Sicurezza e la ricostruzione dei centri Storici in area sisMIca (technologies for the improvement of safety and the reconstruction of historic centres in the seismic area)-aims to provide tools and methods for risk reduction and seismic improvement of Lazio's cultural assets and centres, causing research, intervention policies, and planning to interact in order to support reconstruction choices and foster dialogue with local parties and enterprises. One of the SISMI project's main elements of innovation consists of preparing modes of integration of knowledge and assessments relating to the various components of a territory's vulnerability and seismic hazard that can be used in other seismic territories. SISMI project, tested in seismic territories of Central Italy, is a methodology of integrated, multidimensional, and transdisciplinary investigation, in the conviction that the safety of the territory and of historic and cultural assets is the result of a dynamic risk reduction process capable of guaranteeing and promoting the local communities' resilience, in which both physical/structural and sociocultural elements collaborate.
\end{abstract}

Keywords: seismic vulnerability; hazard profiles; risk management; community resilience

\section{Introduction}

In Italy, the past 50 years alone have seen 18 major seismic events with magnitudes equal to or upwards of 5.8, and eight of them have been catastrophic (greater than or equal to degrees IX-XI on the Mercalli scale) [1]. The number of dead, injured, and homeless, as well as the enormous damage to dwellings, to historic and artistic heritage, and to productive activities bear witness to our territory's extreme physical vulnerability [2]. The financing allocated for the rescue, emergency management, and reconstruction phases during the 1968-2016 period, from the Belice earthquake to the more recent one that struck Central Italy, is estimated at about $€ 125$ billion. However, the most worrisome datum is that aside from the Friuli earthquake of 1976, all the other reconstruction processes are in fact still open, having never been wholly concluded. In Irpinia, for example, these processes will continue at least until 2023 (43 years after the event); in Emilia, Abruzzo, and Central Italy, until 2047, with an additional $€ 35$ billion committed to being spent [3].

The post-seismic reconstruction of the internal areas of Central Italy is, therefore, a serious and recurring problem.

Enormous damage, high costs, and very long times are closely connected also to the great weight of the historic heritage in the stricken areas. The 2016 earthquake in Central Italy struck a territory with more than 6700 buildings of historic and artistic value and a stock of approximately 70,000 real estate units [4]. In approximately four months (from 24 August 2016 to 31 December 2016) Comando Carabinieri Tutela Patrimonio Culturale (the Carabinieri corps's cultural heritage protection command) secured 8062 assets (3843 in Umbria; 2618 in Marche; 1581 in Lazio; and 20 in Abruzzo) [5]. 
For this reason, the Lazio region has initiated a innovation and development project targeted to seismic territories within the Centro di Eccellenza DTC Lazio-infrastruttura di ricerca per la conservazione, valorizzazione e promozione del patrimonio storico-artistico e culturale della regione (centre of excellence, Lazio technology district-research infrastructure for the region's conservation, valorization, and promotion of historic/artistic and cultural heritage), tasked with promoting maximum integration between advanced research (Lazio's universities and national research bodies) and the business world [6].

The project, named SISMI-Tecnologie per il miglioramento della Sicurezza e la ricostruzione dei centri Storici in area sisMIca (technologies for the improvement of safety and the reconstruction of historic centres in the seismic area)—sees the participation of four universities (Sapienza; University of Rome 3; Tuscia University and University of Cassino); CNR, INFN and ENEA, and includes the involvement of 16 research centres; 35 professors and senior researchers, and more than 30 junior researchers, fellows, and grant recipients [7].

In keeping with the objectives of the Centre of Excellence, the project aims to provide tools and methods for risk reduction and seismic improvement of Lazio's cultural assets and centres, causing research, intervention policies, and planning to interact in order to support reconstruction choices and foster dialogue with local parties and enterprises, according to an internationally shared approach [8-10].

The project's objectives are to assess the settlements' vulnerability, also to prepare a model that can be used in other seismic territories, and at the same time to refine the methods for assessing local hazard [11].

As is known, to guarantee risk prevention and governance, a rigorous assessment of the vulnerabilities and of local hazard conditions must be prepared, in accordance with the known definition of Risk (R) as an overall product of Vulnerability (V) and Hazard (P) factors.

The search for effective models in the different phases-prevention, adjustment, and reconstruction - presupposes rigorous and verified methodologies to measure and assess vulnerability and hazard, capable of adjusting to increasingly advanced technologies and tools.

It seems necessary in particular to go beyond the rigid models of the past while facing some problems recurring in our country:

- Fragmented and hard-to-use knowledge of historic heritage. Although Italy has a well-established tradition of investigations aimed at knowledge of the historic heritage and of local construction techniques [12,13], aimed also at seismic prevention, the lack of a common procedure for integrating, implementing, and reproducing knowledge prevents its successful use, particularly by public administrations that are always in the dark about what was produced. Each time, work starts over from square one, without capitalizing on the previous experiences, and casting doubt on reconstruction models in the name of specific territorial traits that certainly do exist, but in this way end up becoming more of a limitation (particularism and localism) than a resource (valorisation of differences within a framework of general consistency). This gives rise to the need to outline methodologies capable of emphasizing local specificities (constructive, seismic, etc.) but at the same time of guaranteeing a framework of general consistency, one that can be reproduced and capitalized on, so as to optimize the large quantity of existing data. Aware of Italy's role in urban conservation on a global scale and the role that knowledge of traditional techniques, materials and methods can play in both the reconstruction and resilient construction of historic centres (as has been highlighted by the critical analysis of the international literature cherishing replicable methods, protocols and tools that can be easily used to other sites in Italy and abroad, offering an added international value to the project [14-19].

- Outmoded sectorality and methodologies for assessing vulnerability and hazard. The components of a territory's vulnerability and hazard are partly physical, and to a great degree cultural, economic, and social [20]. It is, therefore, necessary to investigate the various components in an integrated, 
interdisciplinary, multidimensional way in order to arrive at a knowledge of the different risk factors, and their interrelationships.

- $\quad$ Limited and outmoded vision of the innovation potential connected with the cultural heritage. Cultural and historic heritage (assets, landscapes, traditions and culture, both tangible and intangible) are seen by all as a central resource for the sustainable development of inner areas. However, it is a research whose limits and possibilities appear not to have been examined enough to guarantee not only protection but above all new forms of valorisation.

To promote and spread innovative practices of prevention, adjustment, and seismic reconstruction, the SISMI project has pursued the following objectives:

- Identifying the specific components of the seismic vulnerability of a regional territory, by organizing methods and tools for their rigorous knowledge and arriving at a vulnerability assessment using verified, comparable, and implementable methodologies. This involves systematizing and valorising large quantities of historic and restoration studies present in our country, through the re-introduction into circulation and employment of advanced tools of computerization and technological innovation.

- Defining the hazard profiles using new models permitting detailed analyses and assessments relating to the recent past, and in particular, making it possible to determine seismic actions using probability-based approaches able to take account both of the experience gained in previous earthquakes (seismic sequences occurring in recent times) and specific amplification phenomena due to topographical conformation and the submerged geometry of local geological stratifications [21].

- Assessing the levels of interaction among various components of the vulnerability and seismic hazard factors, in such a way as to arrive at an overall risk assessment, that is to say, one capable of systematically correlating factors of physical and social fragility with local hazard profiles.

\section{Materials and Methods}

In order to support choices and activities of local administrations for the seismic improvement of historic centres, the SISMI project proposes a methodology of integrated, multidimensional, and transdisciplinary investigation, in the conviction that the safety of the territory and of historic and cultural assets is the result of a dynamic risk reduction process capable of guaranteeing and promoting the local communities' resilience, in which both physical/structural and sociocultural elements collaborate. Reference [22] The graphic below (Figure 1) shows that reconstruction and seismic improvement are intended as a dynamic process of progressive reduction of risk. Physical structural and socio-economic elements collaborate to this purpose to guarantee the safety of Cultural heritage, but also to promote innovative forms of development, enhancement, and revitalization, and to increase the resilience of local communities. 


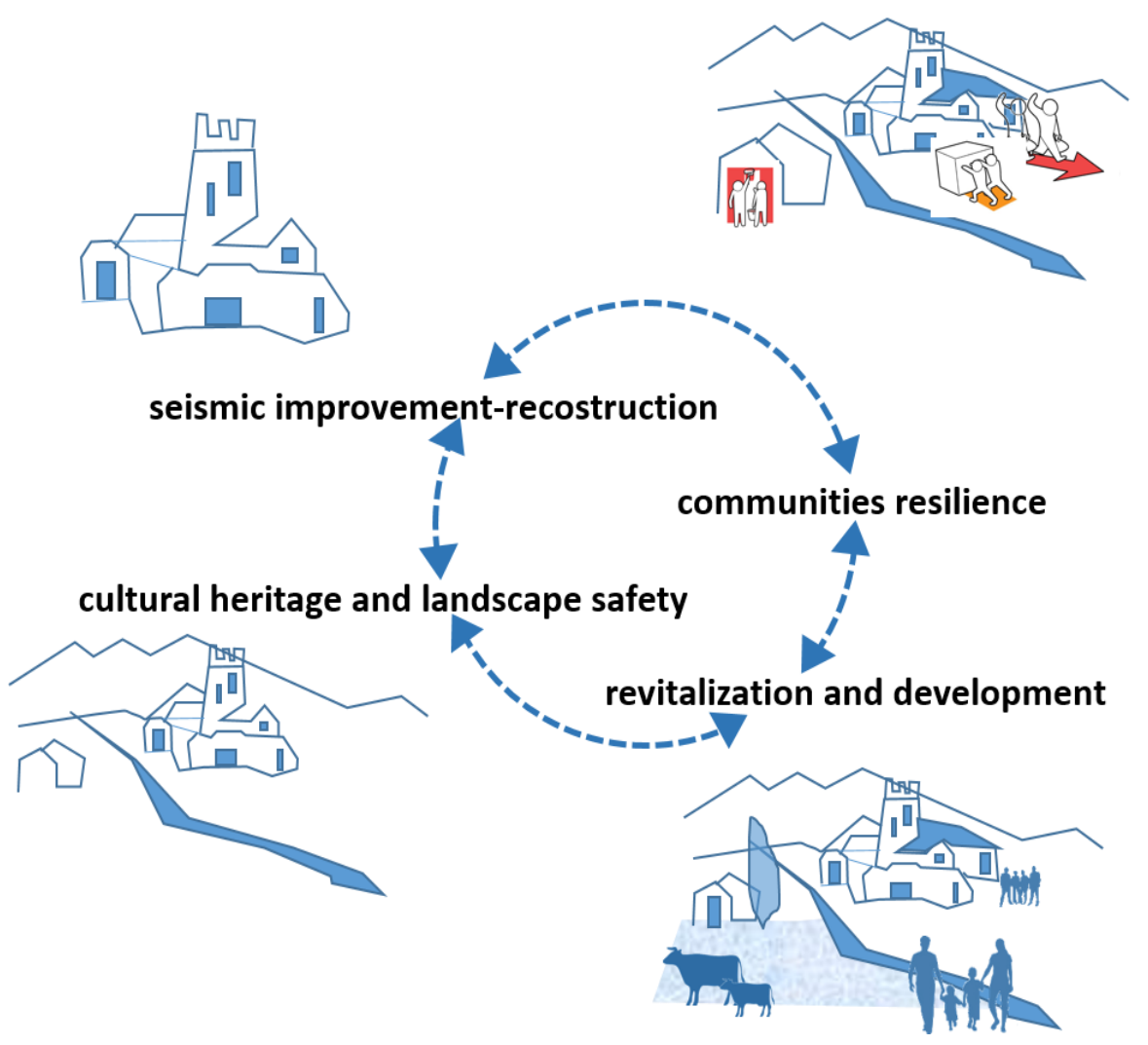

Figure 1. Process of progressive reduction of risk.

\subsection{Modes of Integration of Knowledge and of Research Products}

One of the SISMI project's main elements of innovation consists of preparing modes of integration of knowledge and assessments relating to the various components of a territory's vulnerability and seismic hazard. This is a job that in the first-place entails dialogue among heterogeneous skills and areas of knowledge, that to date have enjoyed scant moments of scientific exchange, thus reducing integration to a poorly effective "formal" moment.

"Transdisciplinarity is the "intellectual space" where the nature of the manifold links among isolated issues can be explored and unveiled, space where issues are rethought, alternatives reconsidered, and interrelations revealed" [23].

In keeping with this definition by UNESCO, SISMI's research has activated an intellectual space adapted to exploring and revealing the connections among diverse subjects, promoting the sharing of different viewpoints and dialogue among topics generally distant from one another, in such a way as to highlight their relationships: in general, by seeking to go beyond the concept of the specialist's purview.

The different working groups interacted via a fruitful exchange of knowledge and data, seeking to demonstrate that reducing seismic vulnerability and implementing effective recovery and prevention strategies requires acting on a number of fronts at the same time, thanks to the synergistic contribution of different professional figures.

A common ground for research allowed the various strains of knowledge to interact and to mutually strengthen one another, as an indispensable prerequisite for preparing innovative scientific products targeting the creation of new resilience profiles.

Each working group made an active and synergistic contribution towards building a knowledge framework and tools capable of supporting decisions and choices by technicians and administrators (so as not to "start over from square one" in the aftermath of a new seismic event), by valorising and developing already acquired skills and intervention methods to be able to act in a more effective and less costly way than in the past (squandering human resources, time, costs, etc.). 
Having clear vulnerability and hazard scenarios means reducing the times and costs for investigations, and above all having a clear picture of the interventions to be carried out before, during, and after the quake.

In the full implementation of the principle of disciplinary collaboration, already declared in the SISMI project's drafting phase, the WP leader and the general coordinator constantly pursued dialogue and the exchange of content among the different disciplinary settings and working groups, through specific modes of organization.

In the first place, although respecting the specific languages of the different disciplines involved in the project (disciplines of history and restoration, territorial, geological, and geotechnical disciplines, disciplines of structural engineering and geomatic monitoring, 3D surveying and modelling, chemical and physical sciences and technologies applied to the conservation of cultural assets, nanotechnologies, materials, sensors and devices for the monitoring of materials and of historic assets, digital technologies for architectural requalification, etc.), attention was given to the appropriateness of preparing a common vocabulary, not as a formal reference, but to guarantee mutual comprehension and maximum consistency of content. In the second place, a single sequence for showing the research work and yielding its results was defined, in order to effectively support transdisciplinary dialogue and the production of products that are easy to disseminate. In particular, each group worked by sharing the "performance objectives" and the "modes of organization" of the research work. As shown in the graphic below (Figure 2) the research was based on three types of activities common to the different working groups. Knowledge, development of technologies and methods capable of optimizing available or acquired data and knowledge to understand what to integrate and implement. Experimenting, experimental application of technologies and methods aimed at defining concretely how to intervene. Monitoring > analysis of results, experiments, achievements aimed at understanding how to improve. the project activities referred to three distinct but interconnected meanings of the term context.

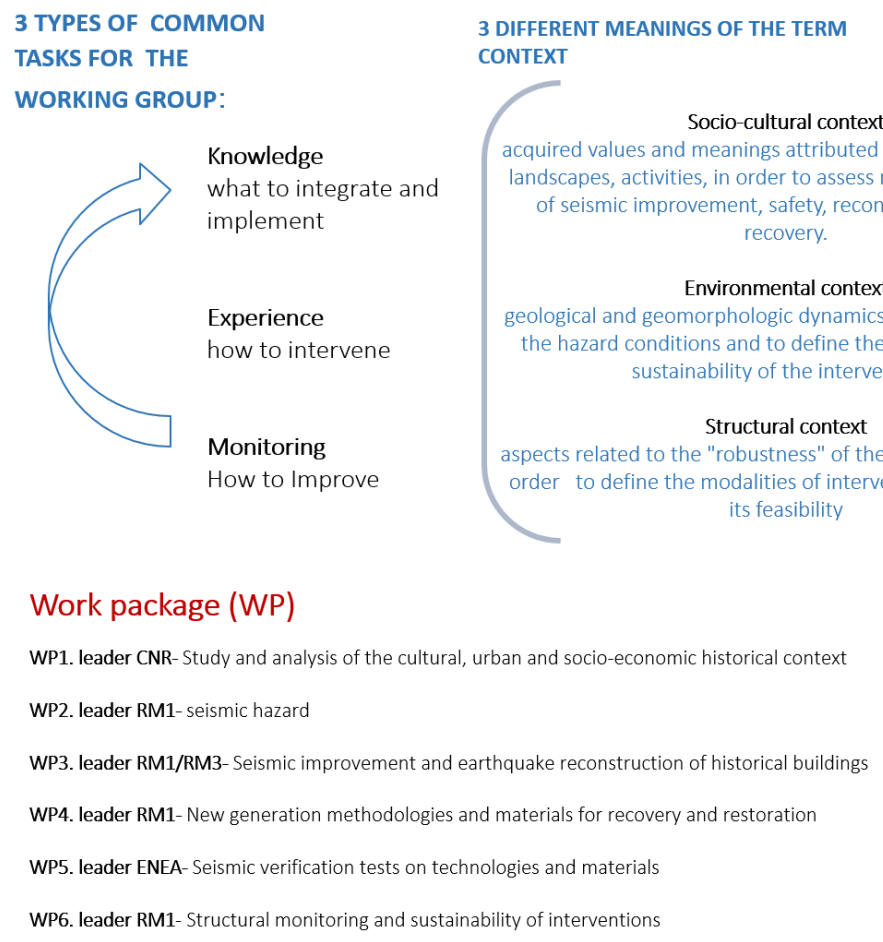

Figure 2. Modes of organization of the research work.

The performance pursued across the different disciplinary groups are oriented towards guaranteeing maximum dissemination and easy public use of the knowledge and methods trialled with the SISMI project, guaranteeing in particular: 
- Innovation: The SISMI project pursued a real advance of knowledge and technologies, proposing, perfecting, or reorganizing precise and detailed modes of interpretation and assessment; and providing indications on the determination of the interventions by means of specific assessments of their effectiveness while proposing the trialling of latest-generation devices and material;

- Accessibility: the expansion of knowledge was guided by the principle of accessibility. Many of the data obtained through the analysis and investigation activities, in fact, merged into databases, websites, and applications-already extant or developed for the purpose-which are continuously updated and easy to query.

- Viability: the scientific results and the methodologies produced are the outcomes of experimentations performed in the study areas (Lazio's inner mountainous areas with high seismicity) or in analogous settings for which the actual possibility for application, understood as the ability to respond to specific and contextual needs, and characteristics, was assessed and tested.

- Performance: experimental activities and methods, designed to obtain meaningful results with respect to the identified objectives and problems;

- Feasibility: the results of the various activities were yielded in the form of instruments-guidelines, calculation tools, workflows-that can be easily used by administrations and their technical offices.

- Replicability: all the results can be generalized and replicated in similar settings. In particular, attention was given to stating not only how to intervene, but "when" and "if" as well, providing detailed parameters based on the time and economies available.

Performance objectives are shown in the graphic below (Figure 3).
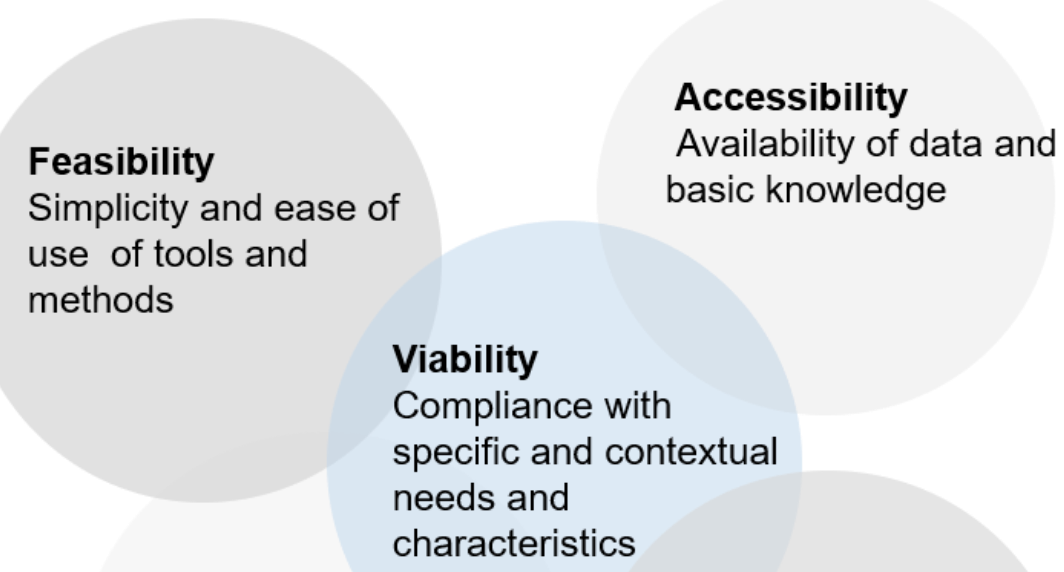

\section{Performance \\ Ability to achieve \\ significant results}

\author{
Replicability \\ Possibility of \\ dissemination in \\ similar contexts
}

\author{
Innovation \\ Ability to produce \\ advancement of \\ knowledge and \\ technology
}

Figure 3. Performance objectives. 
Exchange and dialogue in all working phases-which made it possible to verify, in progress, the results and the interrelationships among groups-were based on a common organizational sequence of the research work:

- Problems: clarifying the problems for which a response is being sought, what difficulties are to be overcome starting from the specific experience of the quake that struck the Lazio region and from the recent reconstruction and seismic improvement experiences. Properly stating the problems makes the arguing and communicating of the project objectives more effective in terms of solutions, minimizations, or clarifications of the problems themselves.

- Methodology: clearly and succinctly illustrating the scientific method followed by each working group, while seeking to emphasize its innovative aspects (advanced research), data used, modes of correlation and interpretation of data. The methodology ascribed to these key elements highlights reliability in terms of result. The succinct definition of the methodology is followed by the more analytical one of the work phases, understood of functional steps definable in terms of both operations to be performed and of intermediate products. This gradual clarification permits easy verification of the work's progress, monitoring it in an orderly fashion.

- Solution or scientific result: each group is required to illustrate, also in progress, the scientific results of the work, in terms of products or procedures.

- Summary products: description of materials and instruments that the project makes available to the Region and to the local Administrations to support choices, dialogue with local parties and stakeholders, and spread knowledge and procedures by disseminating them on the territories, in such a way as to make them "usable" (e.g., guidelines, design criteria, operating manuals, summaries of requirements and performance of innovative materials, etc.).

\subsection{Instruments to Increase Territorial Resilience}

In the SISMI project, the term "territorial resilience" refers to a set of virtuous qualities to be renewed and of shortcomings to be dealt with, taking the concept of resilience as the interaction among specific qualities of a system suitable for reacting to demands for adaptation, profound changes, and acute shocks.

In relation to certain research efforts developed internationally-such as the Japanese Wooden Temporary Housing Group project which, in 2011, following the Tohoku earthquake and tsunami, built emergency housing in wood, with loghouse technology, taking into consideration not only material reconstruction but also the psychological and social aspect of the lives of the displaced persons, while focusing on building a new sense of community for the temporary village [24] - a resilient territory may be defined as a reflexive system, a system that is capable of learning from the experiences of the past; robust, which is to say endowed with physical spaces and infrastructure systems conceived, built, and managed well, in such a way as to take account of the set of risk factors and of all the most advanced experiences for reducing the settlements' vulnerability; reliable, or, more precisely, characterized by high levels of redundancy, which is to say systems capable of withstanding and handling unforeseen events and disturbances (in particular systems of linkage and connection, both tangible and intangible); flexible, which is to say able to metabolize change on the basis of new evidence and various experiences from the past, above all at the level of economic and social activities; enterprising, which is to say capable of achieving objectives of economic vitality and prospects for development via new innovative and creative roads; inclusive, which is to say able to involve heterogeneous sets of people and places; integrated, and used to developing common objectives and ensuring the coordination of efforts. To increase a territory's resilience, a point of view — that of risk - must be actively spread by transitioning from an attitude of defence based almost exclusively on technical, sectoral, and extraordinary measures, to a responsible prevention policy able to reconcile territories, parties, and activities carried out in those territories.

To prevent, it is necessary first of all to have adequate knowledge of the vulnerability, because it is upon this knowledge that it is possible, and a duty, to act, to reduce risks (for the population, 
for cultural and environmental assets, for productive activities, etc.) as well as knowledge targeted to the hazards, and not only seismic hazards, but the hydrogeological, climate-related, and environmental ones that the quake might trigger or amplify.

\subsubsection{Vulnerability-Multidimensional Models for New Forms of Territorial Resilience}

Seismic vulnerability was the object of a transdisciplinary investigation, as the very concept of vulnerability suggests, since it is complex among the various components of fragility characteristic of a territory and of the communities settled on it: structural fragilities of historic centres, of buildings, of cultural assets and of infrastructures; fragility of the systems of territorial relations, both tangible and intangible (territorial cohesion, social, cultural, and economic vitality); fragility of local communities with respect to risk awareness.

To bring into focus a setting's overall vulnerability with respect to the seismic hazard, it is, therefore, necessary to use highly trans-scalar methodologies capable of keeping together vast territories with different types of settlements and links, historic centres, building developments, individual building units and various construction types, with the components related to the settled communities and to their socio-cultural and economic traits, through multidimensional readings that supplement specific spheres of restoration, of the history of architecture and of the city, of architectural and landscape design, of urban planning, of environmental psychology, etc.

The SISMI project has articulated this complexity in relation to certain thematic centres of particular significance in the Lazio area:

a. Inhabited areas-investigations on the vulnerability of historic centres and of their settings, aimed at fostering the protection and safety of the cultural heritage understood as "urban historic landscape."

b. Buildings-investigations on the processes of forming and transforming building types, aimed at identifying weakness due to the evolutionary process of building units and developments and to the characteristics of the construction types, and at assessing consequent damage mechanisms.

c. Construction techniques and materials-investigations on the details and the construction techniques, and on the weaknesses related to traditional construction techniques and materials, supplemented by specific assessments on the effectiveness of pre-modern seismic prevention supports. The vulnerability of historical materials represents a critical issue for the conservation of cultural heritage and its transmission to future generations. To deal with these problems, one of the objectives of the SISMI project assessed the specific vulnerability of historic surfaces (due to physical, chemical and biological degradation processes) [25-28]. In parallel, a methodology for identifying the level of vulnerability with respect to the territorial and urban conformation, the evolutionary processes of urban fabrics, the characteristics of building types and techniques have built and tested in two historic centres: Leonessa and Cornillo Nuyovo. This method, supported by three-dimensional models and a GIS system, allows in elaborating criteria for vulnerability analysis and assessment. Its application in the two case studies of Cornillo Nuovo, and of Leonessa, highlights how it can be easily implemented and is replicable in many different types of historic centres. This wealth of knowledge (seen as an information model) informs the structural analysis of the seismic vulnerability, which this task produced, in relation both to individual buildings and their materials and construction techniques.

d. Landscapes and economies-investigations on the level of vulnerability of the landscapes, understood as the set of historic, cultural, economic and productive relationships among communities settled in the territories, that catastrophic events can weaken or compromise, especially when in the presence of prior fragility and criticalities. In this framework of reference, the landscape is not understood as a background or restriction but as a set of evolutionary relationships, tangible and intangible, those bind territories, communities, ways of living, producing, and using environmental resources, and a central reference in the process of reconstruction, active securing, and economic and social revitalization of the quake-stricken area. 
e. Strategic structures and buildings-investigations on the performance of strategic buildings (schools, production buildings, administrative headquarters) and of architectures for emergencies, in terms of Iconicity (communication of values of safety, reception, identity); compatibility and dialogue with historic settings; functionality and versatility with respect to emergency situations, ordinariness, etc.

f. Community-investigations on the resilience of communities and individuals, and on the modes of relating to risk in its various aspects and different phases.

\subsubsection{Hazard-Multidimensional Models for a Complex Risk Assessment}

To assess seismic hazards in an increasingly reliable way, it appears necessary to link and connect experimental knowledge and different analysis profiles that rely on different methods.

This is, in particular, a question of supplementing the use of already widespread two-dimensional models with three-dimensional models capable of taking into consideration the spatial characteristics of seismic actions, and the possible amplifications linked to the soil's topographical and stratigraphical features. A special, more in-depth analysis is also necessary in order to assess the interactions between earthquakes and other types of hazard (e.g., hydrogeological), as well as the correlations between inhabited areas and the road network. These aspects were investigated through a specific articulation of the research work that allowed the following issues to be put into focus:

a. Basic hazard-reorganization of the investigations aimed at defining the basic seismic actions, and that is to say at creating a system of knowledge for the determination of seismic actions in ideal/simplified/uniform conditions as the basis for subsequent characterizations.

b. Possible amplifications of the risk, linked to topographic and stratigraphic features-preparation of three-dimensional and two-dimensional models for knowledge and assessment of the local seismic response of an entire inhabited area, based on amplification phenomena linked to specific topographic and stratigraphic arrangements.

c. Possible amplifications of the risk linked to combined hazards (landslides induced by earthquakes) on road infrastructures-investigations aimed at a probability-based identification of road infrastructures that may be involved in quake-induced landslide phenomena.

\section{Results}

The SISMI project, according to the aims of the Centre of Excellence for the Lazio Region DTC, promotes the use of innovative technologies, favouring their transfer and dissemination in favour of the multiple stakeholders involved in the improvement of the safety of Cultural heritage in seismic areas.

The main results of the project, therefore, consist of:

- Actions of technology transfer and capacity building, aimed at public administrations. Although focused on a specific sector of protection of cultural assets, and the sector relating to seismic improvement and to post-event reconstruction, the project will contribute towards a greater awareness of the possibilities and opportunities for recovery of assets and historic centres, and of the risk conditions related to buildings, urban systems, and settled populations.

- Innovative instruments and technologies able to permit an advance in seismic improvement activities and knowledge, supporting regional activities and choices relating to the procedures for but above all the appropriateness of intervention (not only "how to intervene" but "when" and "if"), with reference to individual assets, groups, and architectural complexes, but also to urban systems of historic and cultural relevance.

- Building a framework of knowledge in support of decisions and choices that make it possible not to have to "start over from square one" after every seismic event, in order to be able to act in a more effective way that squanders less in terms of resources, time, and costs.

In detail, the results of the SISMI project are the following. 


\subsection{Vulnerability Profiles-Historic Centres, Buildings, Construction Techniques}

3.1.1. Implementation of the MIBACT (Ministry of Cultural Heritage and Activities and Tourism) Risk Map with Specific Purposes of Seismic Adjustment and Prevention

Surveys, studies, and experimental assessments conducted on two sample inhabited areas of Cittaducale-the seismic crater of 2016, and Genazzano (not quake-stricken) made it possible to amplify, in a targeted way, the information contained in the datasheets of the Risk Map drafted by MIBACT [29]. This Map, which covers all of the national territories, in fact, contains information on the buildings' vulnerability, supplementing data relating to: the building's overall morphology, characteristics of the historic construction systems and supervening transformations, signs of decay and instability. This makes it possible to monitor the "health" of historic centres, independently of the scenarios of seismic risk. The experimental work carried out in the SISMI project allowed the following to be prepared:

- new items on the datasheet, corresponding to additional and specific information on the significant construction features, to characterize the structural and antiseismic behaviour of buildings (internal voids, corridors or separations between different buildings, foundations on outcroppings of rock, transformations, consolidations, modern subdivisions of construction units, etc.)

- new models/algorithms of calculation of the interrelationships among different elements, transformations, and fragility in an antiseismic perspective, also using confidence indices capable of assessing the reliability of the information while taking account of the difficulty or impossibility of accessing damaged buildings.

- $\quad$ specific seismic vulnerability indices applicable to the individual building and urban units (groups of building units) that make it possible to calculate the total vulnerability of the Historic Centre, no longer as a simple average of the vulnerabilities for the individual Urban Units, but as overall and actual vulnerability, thanks to the assessment of actual vulnerability derived from discontinuity, even partial abandonment, collapse, etc.

- validation of data and methods that may be applied to all historic centres at seismic risk, supplying local administrations with instrumentation capable of elaborating the risk values upon which to base the decisions relating to intervention priorities. This instrumentation aims to adapt, to the needs of diffuse construction, the instruments and procedures already prepared for architectural, archaeological, and artistic assets [30,31].

\subsubsection{Development of 3D Models and Systems for the Gathering of Georeferenced Data}

3D models and systems for the gathering of georeferenced data can be queried and implemented to systematically interrelate information on the settlements' characteristics and seismic vulnerabilities. Data were gathered and organized with regard to territorial conformation, the conformation of the urban development, evolutionary processes of urban fabrics, the characteristics of building types and construction techniques originating from different sources (direct surveys, cadastral mapping, photographs, open-source photos and maps like Google Earth and Google Street View, iconography and historical documents), constructing an information system that also permits pre- and post-quake virtual $3 \mathrm{D}$ reconstructions [32-34]. The purpose is to access, with continuity, all the information available for the vulnerability assessment on five different scales: territorial, urban settlement, urban fabric, building, details and construction techniques, and their interrelationship. The method was developed and tested on two different inhabited areas: Cornillo Nuovo-a district of Amatrice highly damaged by the 2016 earthquake, and Leonessa-a centre of the crater little damaged by the 2016 earthquake. A database was prepared that contains, organizes, and makes available the following data:

- information on the state and evolution of the centres prior to the quake, of use for both knowing and conserving the memory of what was damaged by the quake (also in the case that it was irreparably destroyed), permitting its virtual reconstruction; 
- information pertaining to construction techniques, local structural systems, and pre-modern antiseismic supports, correlating them to the state of damage in order to have a catalogue of effective solutions for guiding interventions to reconstruct historic buildings;

- information on the post-quake interventions, so as to have the system function also for the purposes of documenting the progress of the works of seismic adjustment and reconstruction.

The GIS that allows storage and implementation of acquired data listed above, is a tool useful for the public administration in order to face future traumatic events. Data are organized in the following layers:

- data relating to the urban structure and its historical evolution,

- data relating to the urban fabric,

- data relating to buildings,

- data relating to construction techniques (walls, vaults, floors, roofs, ceilings),

- data relating to seismic prevention measures (spurs, arches, chains),

The graphic below (Figure 4) shows the case study of the village of Leonessa, in the Rieti's province, which is particularly significant for its urban features and for the quality of the historical buildings, not so altered by recent interventions and equipped with several traditional anti-seismic constructive elements. Starting from the acknowledgement of a local seismic culture, expressed in constructive techniques careful to the problems caused by the frequent earthquakes which stroke the Italian historical centres, the study lead by Michele Zampilli wp 1, deals with the different scales of the anthropic space: territory, settlement, urban fabric, buildings and constructive techniques.

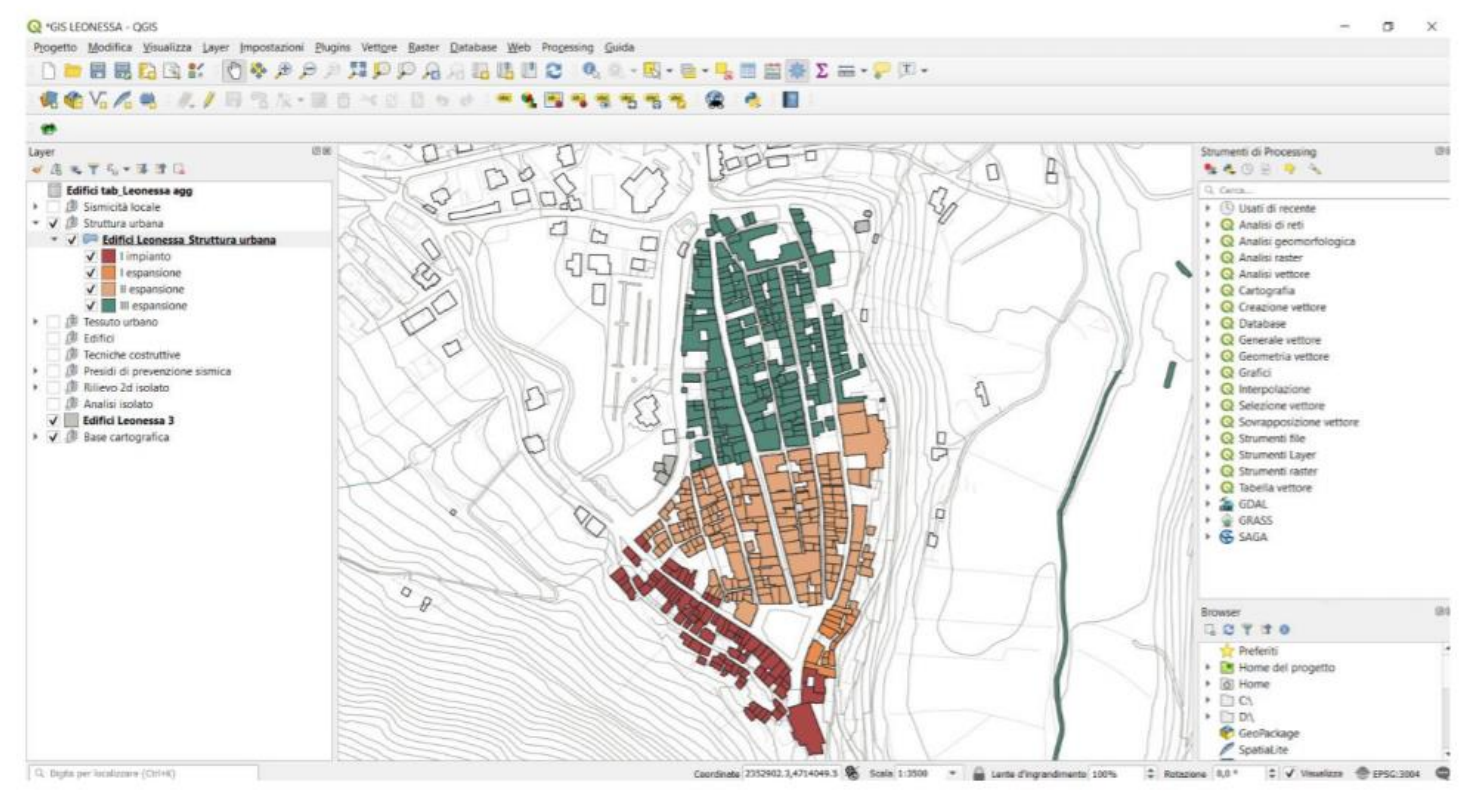

(a)

Figure 4. Cont. 


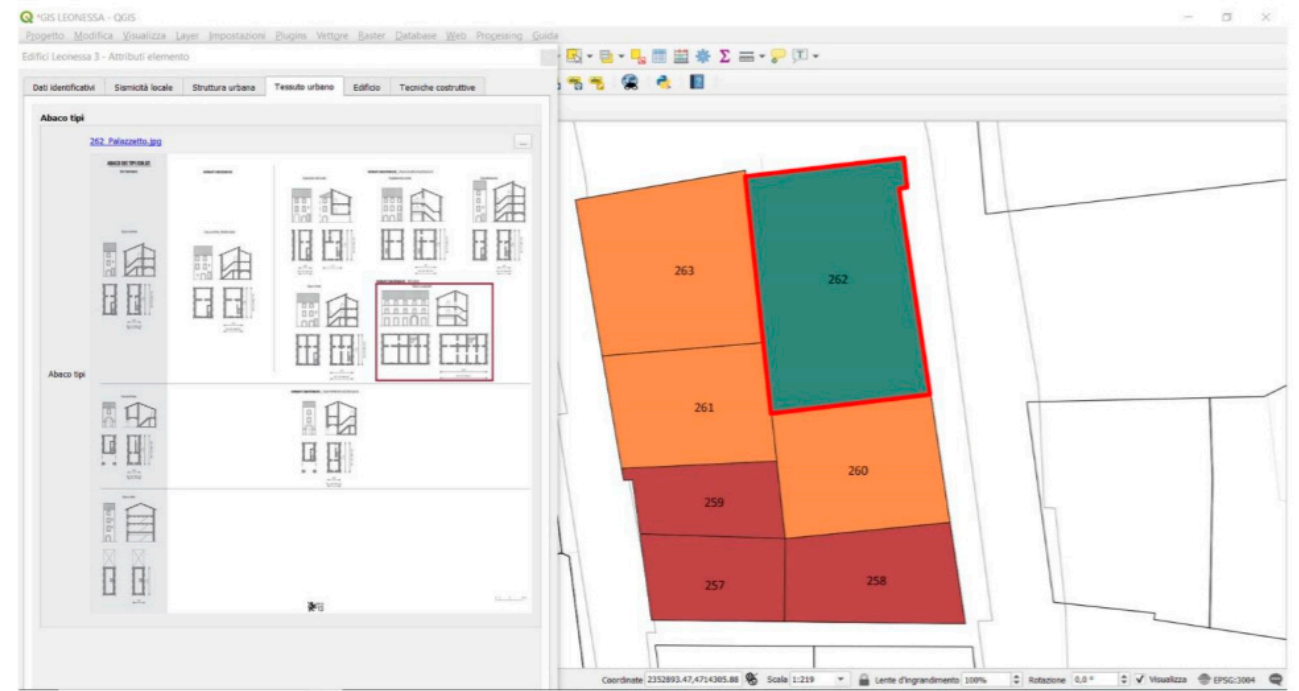

(b)

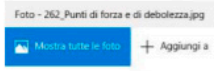

2 (1) 0 औ

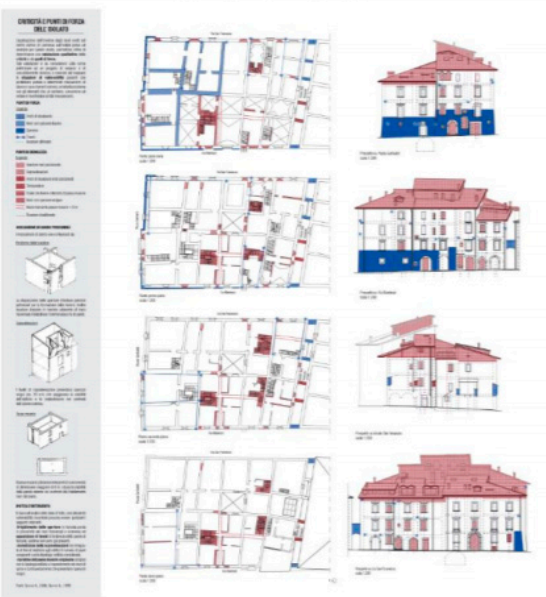

(c)

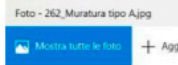

2. 0 . 0 \%
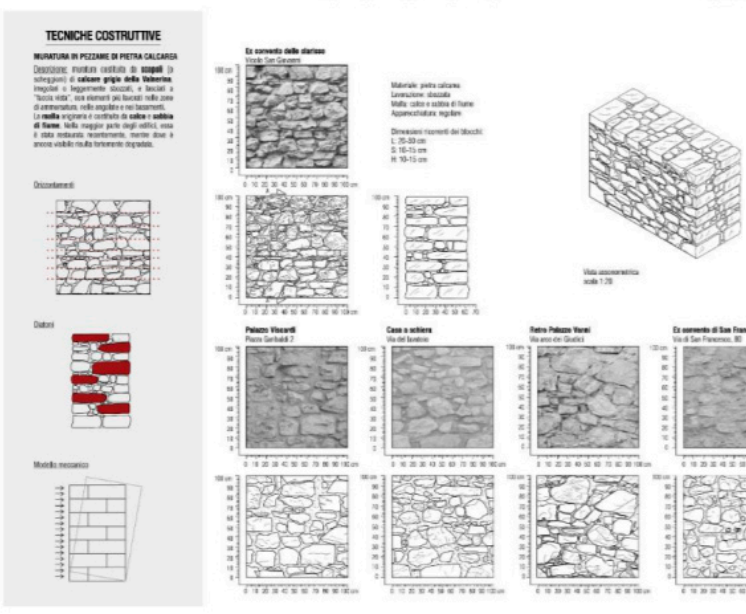

$\pm$
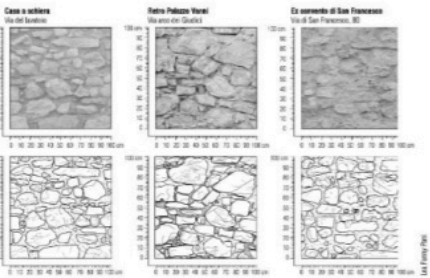

(d)

Figure 4. Cont. 


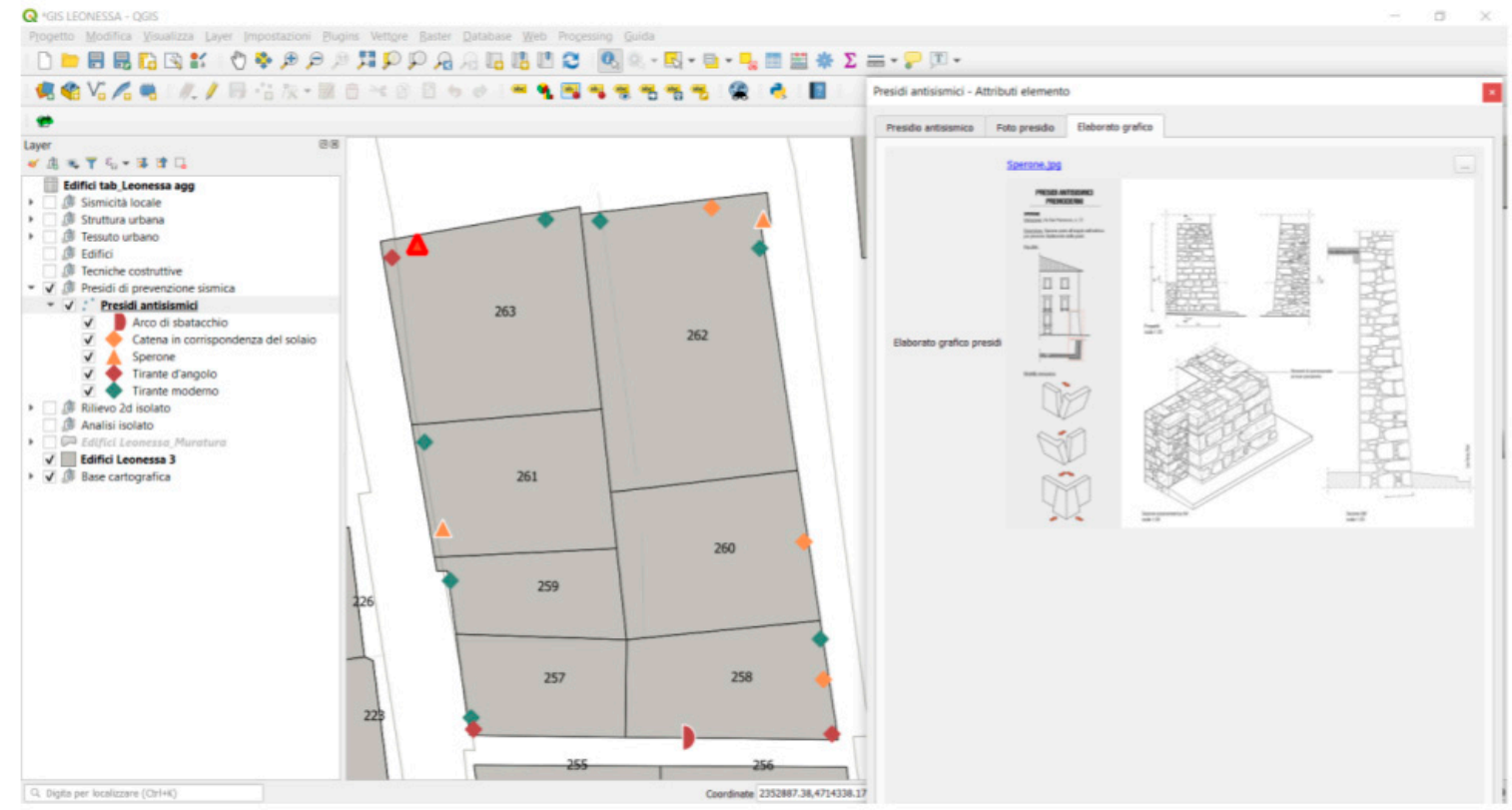

(e)

Figure 4. Analysis at different scales of the anthropic space: territory (a), settlement (b), urban fabric (c), buildings (d) and constructive techniques (e).

\subsubsection{Seismic Verification Test on Technologies and Materials}

The objective of the SISMI project was to support local policy administrators to identify concrete and practicable possibilities for reconstruction of the historic centres affected by the 2016-2017 seismic sequence in Central Italy. An integrated approach was proposed, starting from the consideration that both technological and socio-cultural elements contribute to the post-seismic reconstruction. An excellent example has been the citizens of Collespada, a community of the municipality of Accumoli (RI) heavily damaged by the 30 October 2016 earthquake. They have shown interest in participating in the experiments on structural consolidation and seismic improvement technologies carried out in SiSMI Project. The experimental campaign pursued the general objective of providing results and simulations of the seismic behaviour of historical structures, the effectiveness of interventions and, at the same time, disseminating test methods and results about the seismic verification on materials and technologies for the reconstruction of masonry structures. The experimentation was aimed at verifying technologies and methods already scientifically mature and available, and at the same time communicating their effectiveness through active participation of the citizens at the seismic experiments, both directly in the laboratory and by remote connection, via the internet, with the possibility of communicating and dialogue with researchers during the tests. This sharing approach proved to be so successful that during the experimentation the citizens of Macchia Nord, another community of the Accumoli district, expressed interest in participating in the future experiments. The communities, thanks to their resourcefulness, sense of belonging and identity spirit, constitute a strong stimulus for post-earthquake reconstruction.

\subsection{Vulnerability Profiles-Settings and Communities}

\subsubsection{Preparation of Maps and Indicators to Measure Territorial Resilience}

Maps and indicators measure territorial resilience [35,36] from the standpoint of the vitality of the evolutionary relationships that bind territories, communities, and ways of living, producing, and using environmental resources, for the purpose of assessing vulnerability, shortcomings, and obstacles to post-earthquake socioeconomic recovery: 
- indicators relating to territorial coverage of inner areas: depopulation, ageing population, tendency to abandon centres, and relationship with recent settlement expansions, presence of unused second homes, abandonment of agricultural activities and consequent increase in hydrogeological risk, unmaintained infrastructure, etc.

- indicators relating to the fragmentary nature and backwardness of tourism and hospitality offerings: presence of tourism, seasonal and sectoral offerings, endowment and multifunctionality of hospitality facilities, interconnection among different types of tourism and hospitality offerings, networks and supply chains, etc.

- indicators relating to the low recognisability of the territory, of agrifood productions of excellence, local historic and cultural indicators relating to: the relationship between landscapes, products, and tourism and hospitality offerings; growing identification as unsafe, abandoned territory, particularly after the earthquake.

The graphics below show orography, settlements and demographic trends of the municipalities of Rieti included in the seismic area; the hydro-geological risk (landslide areas in yellow, floodable areas in blue) and the tendency to depopulation due to territorial and economic fragility prior to the earthquake (inhabited houses are in dark blue, in light blue the empty ones) (Figure 5).

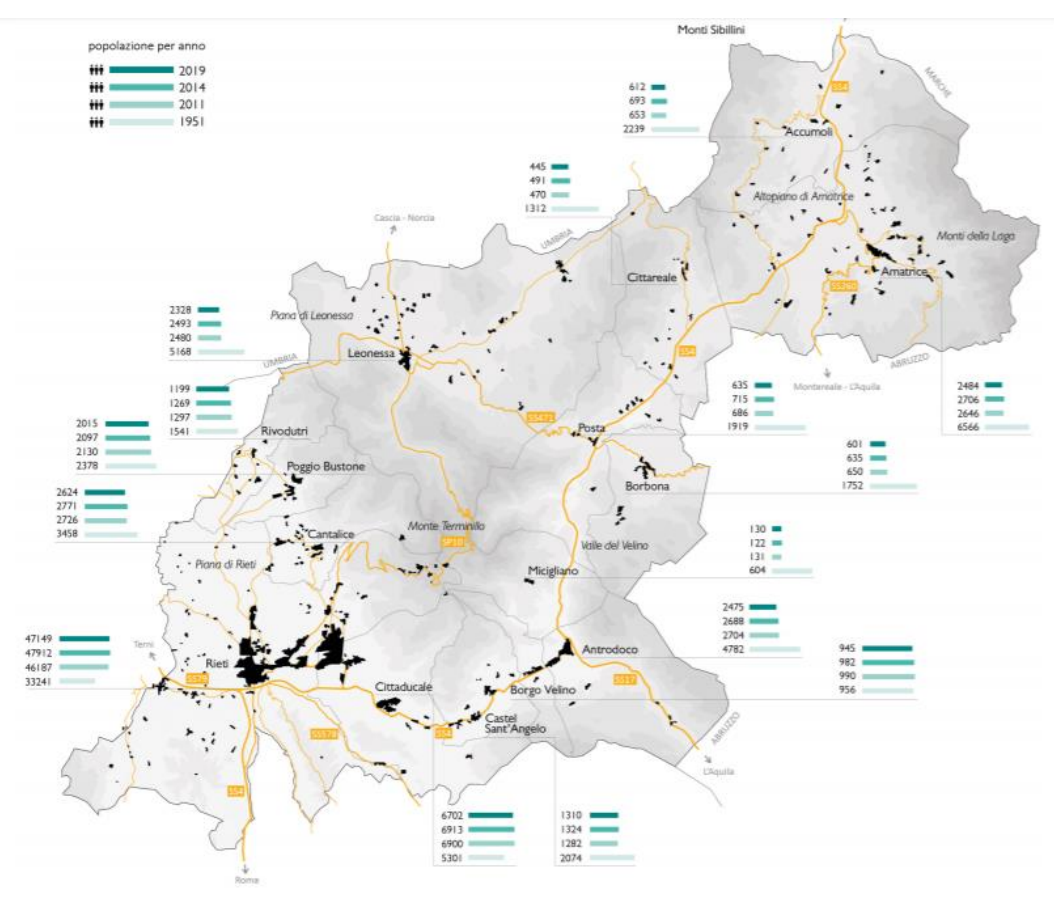

(a)

Figure 5. Cont. 


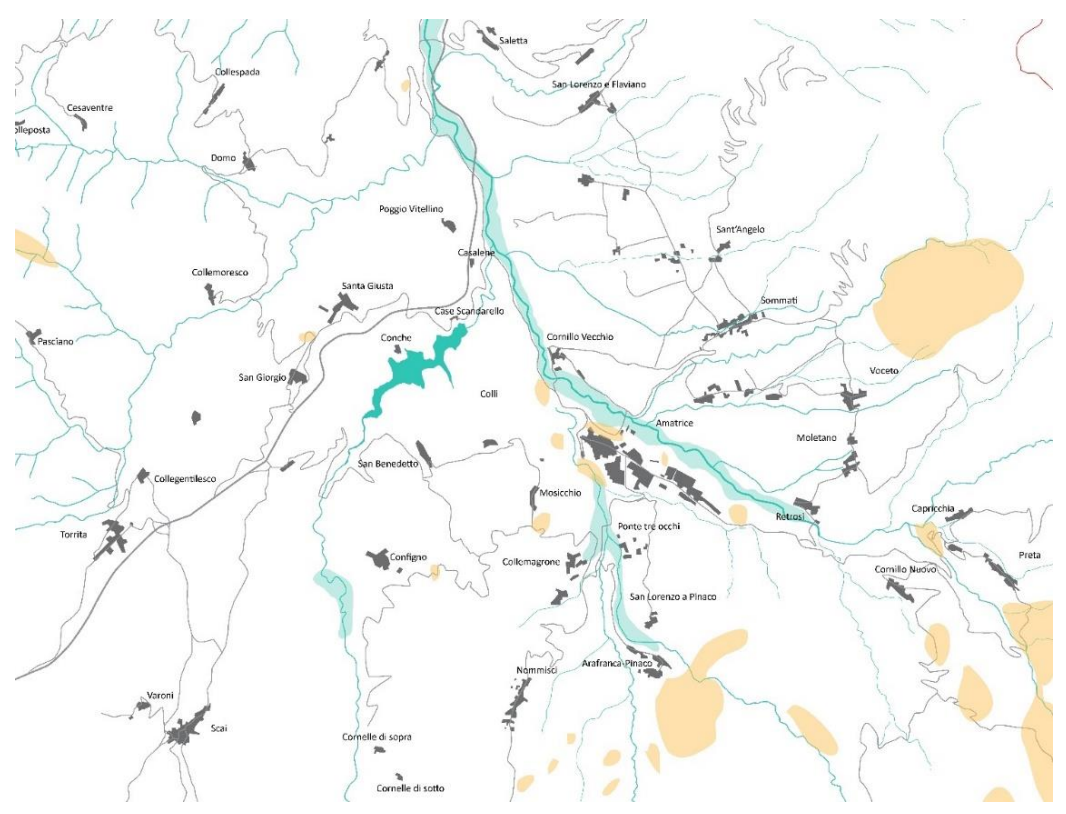

(b)

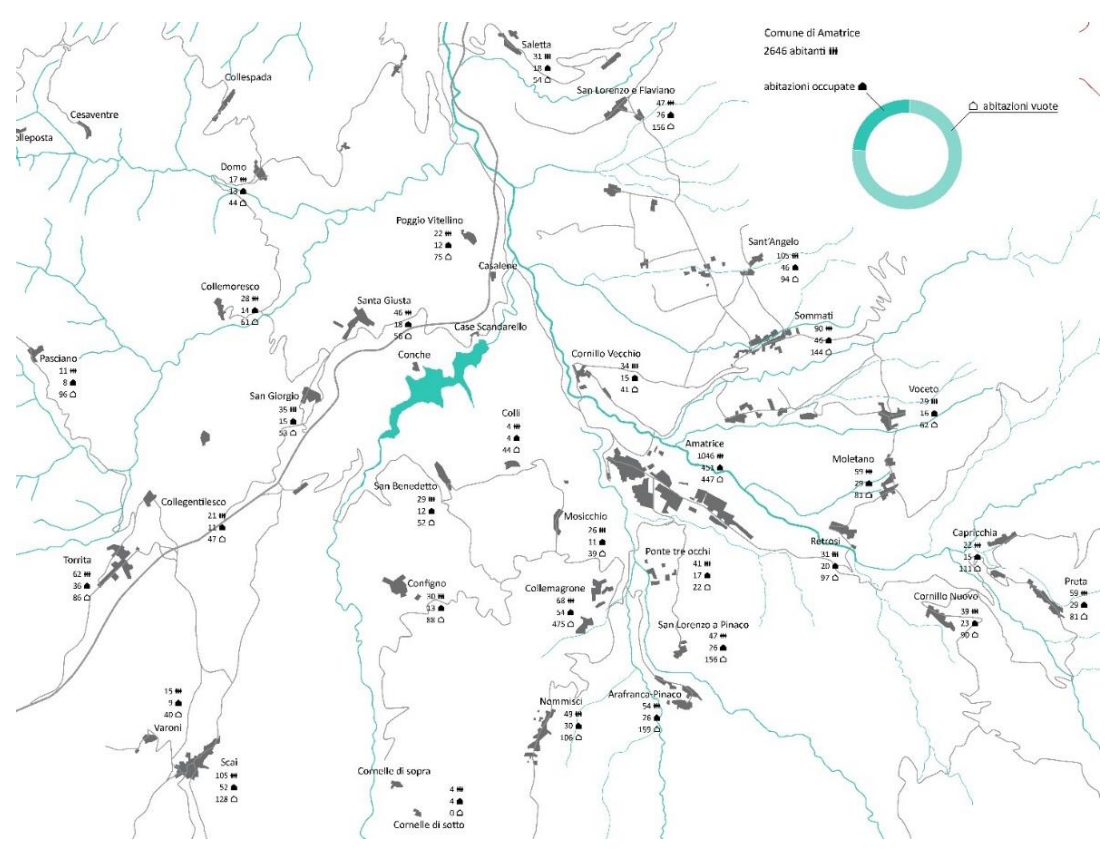

(c)

Figure 5. Orography (a), settlements (b) and demographic trends (c).

3.2.2. Preparation of a Set of Indicators to Assess the Resilience of Individuals and Communities

A Set of Indicators Assesses the resilience of individuals and communities in the different phases of a seismic event (Preparedness, Recovery, and Response) [37]. The indicators, validated and field-tested (in a centre of the crater and at ENEA during a seismic verification test) make it possible, in similar contexts, to have a comparable and reliable measurement of various factors of psychological and social resilience:

- Factors of individual/risk relationship: perception of the risk; subjective knowledge; objective knowledge; previous experience. 
- Factors of individual/community relationship: sense of community; attachment to the home; social norms; social identity; social identification with others affected by the disaster; faith in institutions

- Individual factors: feelings of self-effectiveness; fatalism

\subsection{Vulnerability Profiles-Strategic Buildings and Emergency Architectures}

Preparation of a Grid of Criteria for Assessing the Functional and Symbolic Performance of Strategic Structures

A grid of criteria was prepared to assess the functional and symbolic performance of strategic structures (locations of government bodies, civil protection, healthcare facilities, etc.) through a critical selection of case studies pertinent on an international level (with reference to both temporary and permanent developments) and reconnaissance in Lazio and national territory of case studies that are significant and can be compared with international experiences [38]. The following have been prepared:

- catalogue of solutions and best practices, organized for different parameters (intended use, size of the intervention, materials employed, purpose, function, duration of the life or use cycle, placement in the urban context, versatility and transformability) and in different phases of life, distinguishing 3 macro-categories: emergency character; temporary character; permanent character.

- criteria functional for assessing the effectiveness and replicability of the interventions, also in settings affected by a logic of prevention or of intervention over the long term, and not only of intervention in an emergency condition.

- Test of the criteria through international planning workshops and seminars.

\subsection{Hazard Profiles-Seismic Amplifications}

\subsubsection{Preparation of Three-Dimensional Models for the Assessment of the Seismic Response}

Three-dimensional models assess the seismic response of the entire inhabited area and of the phenomena of amplification of seismic actions in relation to the particular geometric and topographic features generally not considered in the usual studies of seismic response for individual buildings or individual parts of the inhabited area $[39,40]$. The results of the simulation-conducted with respect to the inhabited area of Amatrice-were organized in such a way as to be used by specialized technicians as a supplement to the seismic actions defined by the technical regulations in force for the protection of existing and new constructions, and consist of:

- Identification of the model to faithfully reproduce the topographic conformation of the inhabited area and to describe the submerged geometry of the main stratigraphic units.

- Determination of the mechanical properties of the terrain, through specific experimental procedures (direct method) and through measurements of the amplification produced by environmental vibrations (indirect method for deeper units)

- Definition of seismic actions to be used in the simulations in accordance with probability-based procedures (in the study in question, the decision was made to consider seismic actions more severe than those that would be used in the design of buildings of ordinary importance $(10 \%$ in 50 years), choosing the probability of surpassing equal to $5 \%$ and to $2 \%$ over 50 years).

- Identification of the lower contour of the numerical model. (bedrock seismic) on the basis of the available seismic recordings.

- Validation of the calculation model through comparison with the experimental data relating to measurements of environmental noise amplification and to seismic recordings available in the inhabited area of Amatrice. 


\subsubsection{Preparation of a Two-Dimensional Numerical Model}

Two-dimensional numerical model represents an extension of the existing seismic microzoning studies to take account of seismic actions associated with longer return periods and the effects connected to the particular geometry buried in particular topographic situations (flood basins). The results of the analyses, conducted over the entire municipal territory of Accumoli, consist of:

- New seismic microzoning maps (referring to greater return periods).

- Updated values of the seismic action amplification factors. Analysis of amplification factors (FA).

\subsubsection{Construction of Risk Scenarios}

Risk scenarios assess the outcome of the interaction between the movements induced by landslide phenomena and the road network. The re-elaboration and calibration, with respect to the specific nature of the road network, of the PARSIFAL [40] method, allowed the following results to be obtained:

- Susceptibility analysis: subdivision of the territory into kinematic units, which is to say areas subject to specific landslide mechanisms (falling blocks of rock; translational land slippage on the surface ground of the first activation, reactivations of landslides, including deep ones, in both rock and earth).

- Stability analysis through the use of a set of accelerometer data, compatible with the local seismic hazard, that provides both the likelihood of triggering landslides and the areas' degree of safety.

- Mapping of scenarios that may be referred to earthquake-induced landslides with varied kinematism, along with exposed elements of a strategic nature in the emergency planning (limit emergency conditions and municipal emergency plans, or Piani Emergenza Comunali-PEC).

The results of the analyses with the PARSIFAL approach on specific stretches of road may be aimed at the drawing up of studies on the limit emergency conditions, oriented towards a municipal-level (e.g., municipality emergency plan), provincial, or regional (e.g., provincial forecast and prevention programmes) emergency plan capable of taking into consideration hazard processes that may be correlated directly or indirectly to the occurrence of a quake.

\section{Discussion}

\subsection{Interpretation of Results}

The SISMI projects may be discussed in relation to three different families of objectives underlying the project, directly connected to the third mission activities that are a fundamental mission of the university and of research bodies:

- To promote the transfer of technologies, analysis methods, diagnosis and monitoring, and intervention for the conservation, valorisation, and recovery of the historic and cultural heritage in seismic areas, making them available to final users, administrators, and sectoral experts.

- To contribute towards cultural and social development, as well as the development of civic awareness in the issues of preventing risk in order to increase the resilience of the territories and the communities.

- To contribute to affirming the role of cultural heritage-understood in its broadest sense (assets, landscapes, traditions, knowledge, and skills) in the reactivation and revitalization of disadvantaged territories.

\subsection{Technology Transfer}

The SISMI project constitutes a tangible contribution to the dialogue and to the collaboration between technical/scientific systems, territorial bodies and institutions, enterprise, and citizens, and is based on a real transfer of knowledge, methodologies, and instruments that are easy to practise and 
apply. Through the SISMI in the project, in particular, data, skills, and know-how have been made available, which are the outcome of advanced research and multidisciplinary teams in which the humanities work alongside such disciplines as engineering, geology, chemistry, materials technologies, etc., in a path of collaboration and integration that is hard to put into practice outside of a project like that of the Centre of Excellence, which aims to be a technological research infrastructure and territorial services centre, a point of reference for public bodies (e.g., Superintendencies and municipalities), and above all, for enterprises (artisanal and industrial) in the sector of Cultural Assets.

\subsection{Cultural Development}

SISMI's contribution with respect to the comparison with the dimension of risk is based on the circulation of knowledge, skills, and instruments to increase the awareness of dangerous situations as an essential condition for a functional and forward-looking management of regional territories, as well as the guarantee of safe dwellings and safe towns as a fundamental condition to maintain dynamic and vital communities, and the permanent monitoring as a positive statement of the prevention culture.

\subsection{Affirmation of the Role of Heritage}

The SISMI project has successfully developed research aimed at reaffirming the value of cultural heritage as a fundamental historical and social matrix for mountain territories of the Lazio region. In these so-called "inner areas" (2014-2010 partnership agreement; CIPE deliberates 28-01-2015, no. 9), weakened by a long tendency to depopulation, the earthquake had the most devastating effects, breaking the relationship with the past. The recovery and renewal of this relationship is the starting point for ensuring spaces' safety and community resilience and to create new possibilities for local economies. According to this outlook, the outcomes of project SISMI will mainly strengthen the role of the cultural and landscape assets as a fundamental heritage to guarantee historical continuity, aspirations of the future, and the assumption of natural and social resources as fundamentals of inner areas' recovery.

\subsection{Developments in Progress}

Knowledge, methods, and instruments of investigation prepared to assess vulnerability and hazard are the indispensable basis for supporting regional choices and activities aimed at the conservation, valorisation, and recovery of the historic and cultural heritage in seismic areas. The SISMI project, however, has also aimed to provide specific tools through which to be able to assess needs, opportunities, and priorities of intervention; to identify concrete and practicable possibilities for the improvement and reconstruction of historic centres; to promote the use of innovative methodologies and new-generation materials that can also be verified, tested, and monitored over time (Figure 6).

The project, therefore, developed additional research activities aimed at:

- Allowing an assessment of the actual and specific possibilities for seismic improvement and antiseismic reconstruction (technical, economic, and temporal possibilities that may be practised through simulations in terms of costs and times for a typical case).

- Identifying innovative methodologies and new-generation materials for restoration and recovery, providing parameters for feasibility assessment.

- Disseminating methods and results of the seismic verification tests on the materials for restoration and recovery.

- Providing indications on how innovative structural monitoring systems, low in cost and easy to implement, can also be used by final users (on a large scale), thereby guaranteeing the interventions sustainability. 


\section{Key concepts}

1. The role of the cultural and landscape heritage as fundamental to guarantee historical continuity and aspiration to future

Digital technologies (also open source) that allow continuous, multiple and on time updating and interrogation to support choices of local authorities

Multiscale and multidimensional assessment of heritage vulnerabilities (from landscape scale to mobile goods) to support activities of heritage conservation Authorities

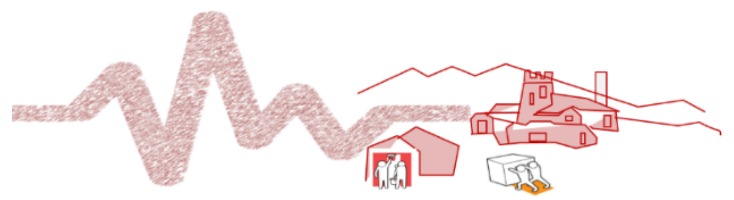

2. The awareness of danger situations as an essential condition for a functional and forward-looking management of regional territories

Innovative models of simulation and monitoring of seismic response of territories to assess the total performance of settlements and infrastructures (including possible interference and amplification effects due to different risk scenarios -seismic, hydrogeological, avalanche,...).

Indicators of psychological and social resilience that measure community responses

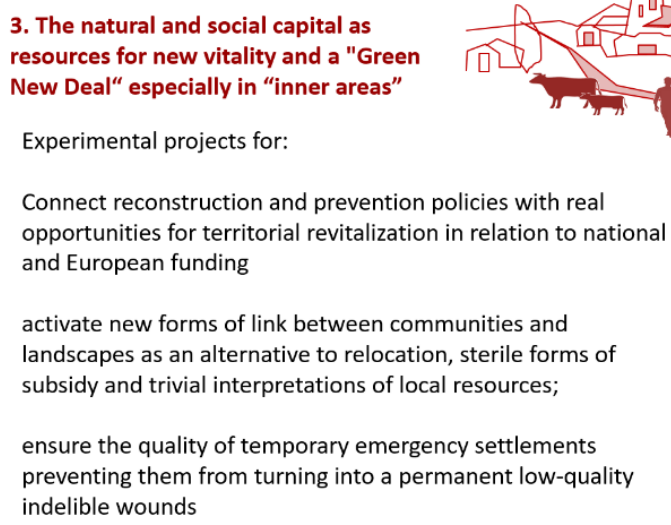

Figure 6. Key concepts.

\begin{abstract}
4. The guarantee of safe dwellings and safe towns as a fundamental condition to maintain dynamic and vital communities

Safe paths and spaces as an opportunity to improve accessibility to essential services for everyday life.

Diagnostic techniques to support differentiated choices in relation to time, cost, levels of safety, and to intervene holistically on urban aggregates, individual buildings and mobile goods.
\end{abstract} 5. The permanent monitoring as a positive statement of the
prevention culture

Development of innovative high-sensitivity techniques and tools, easily installed, minimally invasive and low-cost for continuous monitoring (smart sensors and nanotechnology)

\section{Conclusions}

The project called SISMI-technologies for the safety improvement and the reconstruction of historical centres in seismic areas-was promoted by region Lazio within the Excellence Centre DTC Lazio-a research platform for the conservation, enhancement and promotion of the historical-artistic and cultural heritage of the region, which has the task of promoting the highest level of integration between advanced research (University of Lazio and national research bodies), business world, and regional territories.

The purpose of SISMI project is to support regional strategies and activities aimed at the conservation, enhancement, and recovery of the historical and cultural heritage in seismic areas, providing tools through which needs, opportunities and priorities for intervention can be evaluated; the assessment of the seismic vulnerability and hazard; the identification of concrete and practicable possibilities for the improvement and the reconstruction of historic centres also through 
innovative methodologies and new generation materials, verified, tested and monitored over time. Consistently with the objectives of the Excellence Centre, the SISMI project aims to provide tools and methods in order to reduce the seismic risk [41,42], linking the world of research with the local policies, supporting choices for the reconstruction, and promoting the dialogue between local stakeholders. The SISMI project is based on the dialogue between different disciplines, promoting the idea that the safety of the territories and the historical and cultural heritage $[25-27,29,30]$ is the result of a dynamic risk reduction process, involving both physical and socio-cultural elements, and capable of guaranteeing and developing the resilience of local communities. At first, it is needed to overcome some recurring critical issues, which highlight the importance of "prevention" in territories characterized by a high seismic risk. The knowledge related to the historical heritage and to the interventions for restoration and seismic improvement is fragmented and difficult to use, both in the emergency and in the reconstruction phase. The lack of shared methods to integrate, implement, and reproduce knowledge prevents efficient interventions and feeds the tendency to start again from scratch every time, without enhancing what already exists. A second critical aspect is a sector-based approach. Vulnerability is the resultant of many complex components, so they have to be investigated in a transdisciplinary and multidimensional approach in order to reach a real knowledge of the different risk factors and their interactions [43,44]. Finally, it is needed to renew a limited vision of the potentialities connected to the cultural heritage. The scientific community agrees in considering the cultural and historical heritage (assets, landscapes, traditions, and cultures) a central resource for the sustainable development of the internal areas $[45,46]$.

Author Contributions: Conceptualization, C.I. and L.C.; Investigation, C.I. and L.S.; Methodology, C.I. and L.C.; Project administration, L.C.; Supervision, L.C.; Writing—original draft, C.I. and L.C.; Writing—review \& editing, L.S. All authors have read and agreed to the published version of the manuscript.

Funding: This reserach was funded by DTC_-Distretto Tecnologico per le nuove tecnologie applicate ai beni ed alle attività Culturali, IV Accordo Integrativo Regione Lazio-MIUR-MIBACT—MISE dell'APQ6 “Ricerca, Innovazione Tecnologica, Reti Telematiche".

Conflicts of Interest: The authors declare no conflict of interest.

\section{References}

1. ASMI Archivio Storico Macrosismico Italiano. Available online: https://emidius.mi.ingv.it/ASMI/ (accessed on 16 July 2020).

2. INGV Istituto Nazionale di Geofisica e Vulcanologia. Available online: https://ingv.maps.arcgis.com/home/ index.html (accessed on 16 July 2020).

3. Camera dei Deputati-Servizio Studi-Dipartimento Ambiente, I Principali Eventi Sismici a Partire Dal 1968-Normativa Antisismica, Finanziamenti, Agevolazioni Fiscali e Contributive—Schede di Lettura, in Documentazione e Ricerche Numero: 67. 2009. Available online: http://documenti.camera.it/leg16/dossier/ testi/Am0065.htm (accessed on 17 September 2020).

4. RELAZIONE CONCLUSIVA ATTIVITA' COORDINATE dalla Di.Coma.Ca Seguito Degli Eventi Sismici 2016-2017 del Centro Italia, 24 agosto 2016-6 Aprile 2017. Available online: https:/www.beniculturali.it/ mibac/multimedia/MiBAC/documents/1502211250548_Relazione_del_Segretariato_Generale_MiBACT.pdf (accessed on 17 September 2020).

5. Comando Carabinieri Tutela Patrimonio Culturale. Available online: https://www.beniculturali.it/ mibac/multimedia/MiBAC/documents/1502445346497_Relazione_Comando_Carabinieri_Tutela_del_ Patrimonio_Culturale_pdf (accessed on 17 September 2020).

6. DTC Lazio Centro di Eccellenza. Available online: https://dtclazio.it/ (accessed on 16 July 2020).

7. DTC Lazio Centro di Eccellenza. Sismi. Available online: https://dtclazio.it/sites/default/files/Sismi.pdf (accessed on 16 July 2020).

8. Beck, U. The politics of risk society. In The Politics of Risk Society; Franklin, J., Ed.; Polity Press: Cambridge, UK, 1998; pp. 9-22. 
9. Birkmann, J.; Buckle, P.; Jaeger, J.; Pelling, M.; Setiadi, N.; Garschagen, M.; Fernando, N.; Kropp, J. Extreme events and disasters: A window of opportunity for change? Analysis of organizational, institutional and political changes, formal and informal responses after mega-disasters. Nat. Hazards 2010, 55, 637-655. [CrossRef]

10. Masurier, J.L.; Wilkinson, S.; Shestakova, Y. An analysis of the alliancing procurement method for reconstruction following an earthquake. In Proceedings of the 8th US National Conference on Earthquake Engineering, San Francisco, CA, USA, 18-22 April 2006; Volume 1.

11. Birkmann, J. Measuring vulnerability to promote disaster-resilient societies: Conceptual frameworks and definitions. In Measuring Vulnerability to Natural Hazards. Towards Disaster Resilient Societies; Birkmann, J., Ed.; UNU-Press: Tokyo, Japan, 2006.

12. Brandi, C. Teoria del Restauro; Edizioni di Storia e Letteratura: Roma, Italy, 1963.

13. Marconi, P.; Giovannetti, F.; Pallottino, E. Manuale del Recupero del Comune di Roma; Tipografia del Genio Civile: Roma, Italy, 1989.

14. Oliveira, D.V.; Lourenço, P.B. Protection of cultural heritage from earthquakes: The NIKER project and the related research at UMinho. In Proceedings of the International Conference on Cultural Heritage and Loss Prevention, Porto, Portugal, 6-7 October 2014; pp. 249-260.

15. Macalister, F. Preparing for the future: Mitigating disasters and building resilience in the cultural heritage sector. J. Inst. Conserv. 2015, 38, 115-129. [CrossRef]

16. Murakami, Y. Disaster Recovery and a Society Which Cherishes Cultural Heritage-from the Experience in the Great Hanshin-Awaji Earthquake. In Proceedings of the 34th International Symposium on the Conservation and Restoration of Cultural Property, Tokyo, Japan, 1 July 2012; pp. 79-90.

17. Nishikawa, E. Development of earthquake countermeasures on heritage buildings in Japan. Archeomatica 2017, 1, 34-38.

18. Okamura, K. After the Quakes: The Impact of Disasters on Japanese Archaeology and Heritage Management. Jpn. J. Archaeol. 2017, 4, 191-200.

19. Okubo, T. Traditional wisdom for disaster mitigation in history of Japanese Architectures and historic cities. J. Cult. Herit. 2016, 20, 715-724. [CrossRef]

20. Poljanšek, K.; Marín Ferrer, M.; De Groeve, T.; Clark, I. (Eds.) Science for Disaster Risk Management 2017: Knowing Better and Losing Less, EUR 28034 EN; Publications Office of the European Union: Luxembourg, 2017.

21. Lattanzi, M. Transdisciplinarity: Stimulating Synergies, Integrating Knowledge; UNESCO Documents and Publications; UNESCO, Division of Philosophy and Ethics: Geneva, Switzerland, 1998. Available online: http://unesdoc.unesco.org/images/0011/001146/114694eo.pdf (accessed on 17 September 2020).

22. Faro Convention. Council of Europe Framework Convention on the Value of Cultural Heritage for Society; Treaty Series. No. 199; Council of Europe: Strasbourg, France, 2005.

23. Spita, L.; Capanna, A.; Wooden Temporary Housing Group. Architettura per l'emergenza in Giappone; Capanna, A., Spita, L., Eds.; Il Formichiere: Foligno, Italy, 2020; p. 218; ISBN 9788894805536.

24. Esposito, D. Materiali e Interpretazione Delle Tecniche Costruttive Storiche, in Across the Stones. Immagini, Paesaggi e Memoria. La Conoscenza Interdisciplinare per la Conservazione e la Valorizzazione Della Fortezza del Girifalco; Marino, B.G., Ed.; Edizioni Paparo: Roma, Italy, 2019; pp. 191-196.

25. Zampilli, M.; Brunori, G. Scenari di ricostruzione post sisma. Come definire modalità di intervento. differenziate in rapporto ai danni. In Recupero e Conservazione; REC_Editrice: Arona, Norway, 2018; Volume 149.

26. Giovanetti, F.; Zampilli, M. Dopo il Terremoto... Come Agire? Giornata di Lavoro Sui Recenti Eventi Sismici; TrE-Press: Roma, Italy, 2018; Volume 3.

27. Gigliarelli, E.; Calcerano, F.; Cessari, L. Implementation Analysis and Design for Energy Efficient Intervention on Heritage Buildings. In Digital Heritage. Progress in Cultural Heritage: Documentation, Preservation, and Protection; Ioannides, M., Ed.; Springer: Cham, Switzerland, 2016. [CrossRef]

28. Esposito, C.; Martino, S.; Pallone, F.; Martini, G.; Romeo, R.W. A methodology for a comprehensive assessment of earthquake-induced landslide hazard, with an application to pilot sites in Central Italy. In Landslides and Engineered Slopes. Experience, Theory and Practice, Proceedings of the 12th International Symposium on Landslides, Napoli, Italy, 12-19 June 2016; Aversa, S., Cascini, L., Picarelli, L., Scavia, C., Eds.; CRC Press: Boca Raton, FL, USA; pp. 869-877. 
29. Carta del Rischio del Patrimonio Culturale. Ufficio Centrale per i beni Archeologici; Artistici e Storici-ICR: Roma, Italy, 1996.

30. Fiorani, D. Il Futuro dei Centri Storici. Digitalizzazione e Strategia Conservativa; Quasar: Roma, Italy, 2019.

31. Fiorani, D.; Donatelli, A.; Cutarelli, S.; Martello, A. Vulnerabilità dei centri storici. Validazione della scheda Unità Urbana del sistema Carta del Rischio tramite la sua applicazione su due centri laziali. Mater. Strutt. Probl. Conserv. 2019, 16, 69-96.

32. Canciani, M.; Spadafora, G.; Farroni, L.; Mancini, M.F.; Rinalduzzi, S.; Saccone, M. Methodology of Analysis and Virtual Recomposition: The Case of Retrosi, Amatrice; INTBAU International Annual Event; Springer: Cham, Switzerland, 2017.

33. Esposito, D. Dopo il terremoto: Riflessioni sul metodo e sull'operatività nella ricostruzione post-sismica. Ric. Stor. Dell'arte 2017, 122, 17-22.

34. Zampilli, M.; Brunori, G. Metodi e pratiche per il recupero dell'identità e il miglioramento della sicurezza dei centri storici terremotati dell'Appennino Centrale. In Un Paese ci Vuole. Studi e Prospettive per $i$ Centri Abbandonati e in via di Spopolamento; Oteri, A.M., Scamardì, G., Eds.; SOVERIA MANNELLI (CZ): Reggio Calabria, Italy, 2018; pp. 120-121.

35. Caravaggi, L. Ricostruzione di Territori, in Abitare la Terra 48; Gangemi Editore: Roma, Italy, 2018; pp. 34-37.

36. Caravaggi, L.; Carpenzano, O.; Fioritto, A.; Imbroglini, C.; Sorrentino, L. Ricostruzione e Governo del Rischio. Piani di Ricostruzione Post Sisma dei Comuni di Lucoli, Ovindoli, Rocca di Cambio e Rocca di Mezzo (L'Aquila); Quodlibet: Roma, Italy, 2013.

37. Bonaiuto, M.; Alves, S.; De Dominicis, S.; Petruccelli, I. Place attachment and natural hazard risk: Research review and agenda. J. Environ. Psychol. 2016, 48, 33-53. [CrossRef]

38. Aquilino, M.J. Beyond shelter: Architecture and human dignity. Boundaries 2011, 2, 9-13.

39. Martino, S.; Battaglia, S.; D’Alessandro, F.; Della Seta, M.; Esposito, C.; Martini, G.; Pallone, F.; Troiani, F. Earthquake-induced landslide scenarios for seismic microzonation: Application to the Accumoli area (Rieti, Italy). Bull. Earthq. Eng. 2019. [CrossRef]

40. Luzi, L.; Pacor, F.; Lanzano, G.; Felicetta, C.; Puglia, R.; D’Amico, M. 2016-2017 Central Italy seismic sequence: Strong-motion data analysis and design earthquake selection for seismic microzonation purposes. Bull. Earthq. Eng. 2019. [CrossRef]

41. Martino, S.; Battaglia, S.; Delgado, J.; Esposito, C.; Martini, G.; Missori, C. Probabilistic Approach to pRovide Scenarios of earthquake Induced slope FAiLures (PARSIFAL) Applied to the Alcoy Basin (South Spain). Geosciences 2018, 8, 57. [CrossRef]

42. Fiorani, D.; Acierno, M. Innovative Tools for Managing Historical Buildings: The Use of Geographic Information System and Ontologies for Historical Centers. In ISPRS. International Archives of the Photogrammetry, Remote Sensing and Spatial Information Sciences, Proceedings of the GEORES 2019: Geomatics and Restoration, Milan, Italy, 8-10 May 2019; Brumana, R., Pracchi, V., Rinaudo, F., Grimoldi, A., Scaioni, M., Previtali, M., Cantini, L., Eds.; ISPRS: Milano, Italy, 2019; pp. 21-27.

43. Acierno, M.; Cursi, S.; Simeone, D.; Fiorani, D. Architectural heritage knowledge modelling: An ontology-based framework for conservation process. J. Cult. Herit. 2017, 24, 124-133. [CrossRef]

44. Razzano, R.; Gaudiosi, I.; Moscatelli, M.; Luigi, C.; Lanzo, G.; Martini, G.; Hailemikael, S. Modelling the three-dimensional site response in the village of Amatrice, Central Italy. In EGU General Assembly Conference Abstracts; EGU: Munich, Germany, 2020; p. 22483.

45. Sorrentino, L.; AlShawa, O.; Liberatore, L.; Liberatore, D.; Mollaioli, F. Seismic demand on historical constructions during the 2016-2017 Central Italy Earthquake sequence. In Structural Analysis of Historical Constructions; Springer: Cham, Switzerland, 2019; pp. 1355-1363.

46. Caravaggi, L. SISMI: Dalla Fragilità al Rilancio: Un Progetto per i Centri Storici Delle Aree Interne Colpiti dal Sisma; L'Erma" di Bretschneider: Roma, Italy, 2020; p. 65.

(C) 2020 by the authors. Licensee MDPI, Basel, Switzerland. This article is an open access article distributed under the terms and conditions of the Creative Commons Attribution (CC BY) license (http://creativecommons.org/licenses/by/4.0/). 